\title{
Office of Communications
}

National Cancer Institute

\section{Source}

National Cancer Institute. Office of Communications. NCI Thesaurus. Code C20083.

The Office of Communications encompasses the former Office of Cancer

Communications, The Office of Liaison Activities, and the Office of Cancer Information, Communication and Education. Its mission is to communicate accurate information about cancer and $\mathrm{NCl}$ activities to a wide array of audiences, including: cancer patients, family members, health care providers, community health educators, advocates, Congress, the media, and the general public. 